\title{
AS ESTRATÉGIAS DE TUTORAMENTO EM LIVROS DIDÁTICOS DE PORTUGUÊS LÍNGUA ESTRANGEIRA
}

\author{
FABRÍCIA CAVICHIOLI \\ fabriciacavichioli@yahoo.com.br
}

\begin{abstract}
This paper has the aim of presenting the partial results obtained from the analysis of didactic materials as genres to the teaching of Portuguese as a Second Language (PSL). In order to achieve this goal, this study investigates: $\left.1^{\circ}\right)$ what are the tutorial strategies the teacher's book presents to help both teacher and student's performance; $\left.2^{\circ}\right)$ what is the design presented in the tutorial of reading activities in the student's book. The didactic materials analyses will be based on the Activity Theory (Leontiev). The partial results suggest the teacher's book do not significantly provide scaffolding neither to the teacher nor to the students' strategies, that is, it just gives some suggestion to the teacher. On the other hand, in the students' book, the absence of tutorials was identified.
\end{abstract}

\section{CONSIDERAÇÕES INICIAIS}

A premissa central que norteou o desenvolvimento deste estudo foi a constatação de que alguns materiais didáticos (doravante MD) de Português para estrangeiros, disponíveis no mercado e, consequentemente, adotados pelos professores de PLE, apresentam falhas ${ }^{1}$. Sendo assim, nosso objetivo é fazer uma análise parcial de um livro didático do aluno (LDA) e um livro do professor (LP), com delimitação nas seções de leitura. Delimitamo-nos às seções de leitura, porque a ênfase nesta habilidade tem sido considerada uma estratégia particularmente eficaz para o ensino de língua estrangeira. Segundo Oliveira e Paiva (1997, p.73), um número significativo de educadores vem se dedicando às pesquisas ${ }^{2}$ sobre estratégias de aprendizagem, com o intuito de auxiliar os alunos a obterem mais sucesso na aprendizagem de ensino de línguas estrangeiras. Até então, referindo-se aos dados obtidos, a estratégia de leitura lidera o ranking, sendo considerada um dos meios mais utilizados para se aprender uma língua (Ibidem, p.75).

Os aspectos que nos propomos a analisar dizem respeito às estratégias de tutoramento (doravante ET) ${ }^{3}$ utilizadas nas atividades de leitura. Acreditamos que o professor deveria ter disponibilizadas no LP tais estratégias, a fim de utilizá-las em sala de aula para monitorar e assistir o aluno no processo de ensino-aprendizagem. $O$ LDA também deveria contemplar tipos de estratégias que tivessem como finalidade auxiliar o aluno na compreensão da leitura. Amparados por tais estratégias, tanto o professor como o aluno poderão usufruir desse conjunto de instruções (estratégias de tutoramento), que mediará o trabalho de ambos em sala de aula em Zona de Desenvolvimento Proximal. Só haverá ZDP se houver a interação entre professor e aluno. Segundo Richter ${ }^{4}$, a ZDP pode ser concebida como um espiral de complexidade (o aluno aprende e reaprende, mas em um patamar superior), na qual o aluno 
(re)constrói em cima do que já sabe (é destacado o papel da metacognição no processo). Ressaltamos ainda que este fator se tornou o alvo desta pesquisa não simplesmente pelo fato de acreditarmos que tais estratégias são importantes, mas, sobretudo, porque ao manusearmos alguns exemplares do livro do professor e do livro do aluno, constatamos que havia um déficit bastante significativo neste aspecto.

Entretanto, o propósito deste artigo é, em primeiro lugar, elaborar, apoiados nas estratégias de questionamento oral já existente, estratégias escritas de tutoramento para que professor e aluno tenham subsídios para uma prática em sala de aula; e, em segundo lugar, verificar se os autores dos MD oferecem tais estratégias para o trabalho do professor e aluno.

Torna-se conveniente destacar que as estratégias de tutoramento diferenciam-se das demais estratégias de aprendizagem por um fator chave - a assistência do aluno pelo professor (andaime intersubjetivo) no trabalho didático. Com o uso das ET, o intuito é fazer com que o aluno internalize as estratégias utilizadas pelo professor e passe a reconstruir as suas próprias estratégias. Ou seja, estas estratégias requerem o auxilio do professor no processo de aprendizagem, fator este que se diferencia das demais estratégias de aprendizagem as quais muitas vezes estão preocupadas em apenas dar uma margem de iniciativa ao aluno para que ele realize as atividades sem o auxilio (mesmo indireto, pelo design da tarefa), do professor. Sendo assim, as perguntas de pesquisa orientadoras desta investigação são:

a) Em que medida as estratégias de tutoramento presentes no livro do professor são pertinentes no intuito de ajudar o professor a ampliar o desafio nas atividades de leitura em PLE? b) Que tipo de design tem o tutorial das atividades de leitura do livro didático do aluno, e em que medida esse modelo suscita o desafio das atividades de leitura em PLE?

Para atingir o objetivo central deste trabalho, este artigo será dividido em cinco seções. Na primeira, será realizada a elaboração das estratégias de tutoramento, tendo como base de apoio a literatura pertinente das estratégias de questionamento. $\mathrm{Na}$ segunda etapa, apresentaremos a metodologia norteadora deste trabalho, a Teoria da Atividade na concepção de Leontiev. Em terceiro lugar, a justificativa da escoIha e do procedimento de análise do corpus. $\mathrm{Na}$ quarta seção, a análise propriamente dita dos MD. E, na última, resultados e considerações finais do estudo.

\section{MATERIAL DIDÁTICO COMO GÊNERO}

Conforme recomendado pelos PCNs (1996) da Língua Portuguesa, os gêneros têm como objetivo atender às necessidades do aluno, sejam elas da linguagem escrita ou da linguagem oral. Essa mesma capacidade de se adequar às necessidades é reconhecida nos materiais didáticos, que neste estudo são considerados como um gênero (tomando a linguagem em sua instrumentalidade mediadora dos sistemas de atividade), vale dizer, como um instrumento para o ensino e/ou aquisição do Português Língua estrangeira. O material didático como instrumento, por sua vez, encontra-se entre 0 aprendiz que age e o objeto (= a base conceitual-procedural da competência comunicativa) sobre o qual ele age. Ou seja, tem como propósito mediar as tarefas que os aprendizes desenvolvem. 
Schneuwly (2004) defende a tese de que o gênero é um instrumento. O autor ressalta que um instrumento medeia uma atividade - especifica e direciona sua forma, concretizando-a; mas esse mesmo instrumento pode representar também essa atividade materializando-a semioticamente - isto é, pode atuar como signo dessa atividade. A esse respeito, o autor escreve:

\begin{abstract}
As atividades não mais se presentificam somente em sua execução. Elas existem, de uma certa maneira, independentemente desta, nos instrumentos que as representam e, logo, significam-nas. O instrumento torna-se, assim, o lugar privilegiado da transformação dos comportamentos: explorar suas possibilidades, enriquecêlas, transformá-las, são também maneiras de transformar a atividade que está ligada à sua utilização (SCHNEUWLY, 2004, p.24)
\end{abstract}

Escolhemos um gênero em função de uma situação definida por um determinado número de parâmetros: sua finalidade, seus destinatários e também seus conteúdos. Bronckart (1999), por sua vez, destaca alguns parâmetros, os quais considera essenciais na escolha de um gênero: objetivos, interesses e questões específicas. $O$ autor destaca que:

Os gêneros não podem ser objeto de uma classificação racional, estável e definitiva. Primeiro, porque do mesmo modo que as atividades de linguagem de que procedem, eles são em número de tendência ilimitado; segundo, porque os parâmetros que podem servir como critérios para classificação (finalidade, questão social, conteúdo temático etc) são, ao mesmo tempo, pouco delimitáveis e em constante interação (BRONCKART, 1999, p.138)

Para que os materiais didáticos possam servir de instrumento mediador do processo de ensino-aprendizagem, não podem ser encarados separadamente da esfera social: precisam estar engajados com a realidade dos aprendizes, bem como atender suas necessidades. Seguindo essa perspectiva, temos a oportunidade de conhecermos melhor os conceitos e as crenças construídos pelos alunos. Conforme Bazerman (2005), o sistema de atividades pode nos levar a pensar em questões como:

De que forma os alunos constroem conceitos e conhecimento através da solução de problemas, como as atividades instrucionais viabilizam a construção do conhecimento e oportunidades de aprendizagem; como os instrumentos apóiam e estruturam a aprendizagem; e como, e com que propósitos, as habilidades dos alunos são avaliadas (BAZERMAN, 2005, p.34)

\title{
ZONA DE DESENVOLVIMENTO PROXIMAL
}

A teoria vygotskiana, segundo Frawley (2000, p.102) é muito especifica sobre como examinar as perspectivas de crescimento individual em qualquer exemplo de atividade intersubjetiva. Todavia isso pode ser realizado por intermédio do exame da Zona de Desenvolvimento Proximal (doravante ZDP). ZDP é o distanciamento existente entre o nível de desenvolvimento real, o qual é caracterizado pela autonomia do aluno na resolução das tarefas (resolução independente de problemas), e o nível de desenvolvimento potencial determinado através da resolução de problemas com 
a colaboração de um adulto ou pares mais proficientes. O processo pela ZDP pode ser ilustrado por um modelo de quatro estágios. Gallimore e Tharp (1996, p. 180) comentam que o modelo diz respeito à relação entre controle social e autocontrole.

No primeiro estágio, o desempenho é assistido por indivíduos mais capazes. Antes de desempenhar o papel de atores independentes, os aprendizes dependem da colaboração de adultos ou de colegas mais capazes para realizar suas tarefas. Essa assistência pode ser dada de várias maneiras: perguntas, diálogos, estratégias problematizadoras, pistas, atalhos etc. No segundo estágio, o desempenho é autoassistido. Mas isso não quer dizer que o desempenho esteja plenamente desenvolvido ou automatizado. A regulação pode ter passado do falante adulto para a criança, mas a função de controle ainda se apega à verbalização aberta sob a forma do discurso autodirigido (Ibidem, p. 181). O terceiro estágio caracteriza-se pelo desenvolvimento desenvolvido, automatizado e fossilizado. Os autores explicam tal caracterização:

\footnotetext{
Uma vez desvanecida toda aparência, ou exteriorização, da auto-regulação, o aprendiz emerge da zona de desenvolvimento proximal. A execução de tarefas torna-se amena e integrada: ela foi interiorizada e automatizada. Não há mais necessidade de assistência do adulto, ou de auto-assistência (Ibidem, p. 181).
}

No ultimo e quarto estágio, temos a desautomatização do desempenho que conduz a um retorno à zona de desenvolvimento proximal. Para qualquer individuo, no decorrer de sua vida, o aprendizado segue as mesmas regras e seqüências da ZDP da assistência externa à auto-assistência - a elas retornando reiteradas vezes para o desenvolvimento de novas capacidades (Ibidem, p.182). Recursivamente, esse processo de quatro estágios leva a um aprendizado na forma de uma espiral de complexidade.

Para dar conta desse processo de internalização que é trabalhado na ZDP, Bruner (1977, apud MAGALHÃES, 1994) elabora a noção de andaimes (scaffolding). Conforme Magalhães,

O conceito de andaime, na escola, pressupõe, assim, a avaliação constante dos dois níveis do desenvolvimento cognitivo do aluno, a crescente retirada do suporte do professor e a ação do aluno em assumir cada vez mais o trabalho antes realizado pelo professor (MAGALHÃES, 1994, p.5).

\section{PERGUNTAS: UM ESTUDO RETROSPECTIVO}

Lucioli (2003), em seu trabalho intitulado As perguntas como mediadoras na construção de conhecimentos, faz uma retrospectiva de estudos acerca das perguntas, a fim de verificar de que forma as perguntas, enquanto mediadoras no processo de construção de conhecimentos, são utilizadas nas aulas de língua inglesa (Lucioli, 2003, p.15). Essa retrospectiva incluiu autores que realizam trabalhos científicos sobre perguntas tanto no âmbito nacional como internacional, tais como: Fernandes (1992, apud LUCIOLI, 2003), que se propôs a investigar os tipos de perguntas que eram utilizadas com grande frequêencia nas aulas de inglês e também a que tipo de interação tais perguntas davam origem; Coracini (1995), que enfatiza os tipos de perguntas feitas pelo professor em aulas de leitura; Doff (1988) e Ricardo (2002, apud LUCIOLI, 2003) que discutem e pesquisam sobre os tipos de perguntas. O pri- 
meiro faz referência a três tipos de perguntas, a saber: perguntas fechadas, perguntas que possibilitam opções de escolha e perguntas iniciadas por pronomes relativos. $\mathrm{E}$ o segundo direcionou seu estudo às questões utilizadas em textos científicos de divulgação infantil. Para finalizar, mais dois autores apresentam-se incumbidos da tarefa de pesquisar sobre o uso das perguntas, Martins (2006, p.1) e Gomes (2002). Martins enfatiza a utilização das perguntas em seminários e palavras. Para o autor, perguntar é uma forma de conhecer a verdade, de dar sentido ou validade à abordagem e tema transmitidos durante uma palestra ou aula. E Gomes, por sua vez, apoiado na Teoria da Experiência de Aprendizagem Mediada (EAM), de Reuven Feuerstein, apresenta as perguntas mediacionais, as quais são classificadas pelo autor da referida teoria. Em relação a este tipo de perguntas, Gomes (2002) acrescenta:

Nesta perspectiva, o mediador estabelece uma relação dialógica, oferece dicas e pistas para que a pessoa atinja certo nível de tomada de consciência e mobilização cognitiva impossível de se atingir se o individuo for deixado sozinho. São oferecidas pistas sobretudo atreves de novas perguntas. Na realidade, o método interrogativo deve ser a utilização de uma cadeia complexa de perguntas que induzam o mediado a um conflito e a uma possibilidade de mudança tanto em seu conhecimento prévio quanto em seu padrão espontâneo de raciocínio. (GOMES, 2002, p. 231232)

Na próxima seção, apoiados nesta sumária retrospectiva teórica, realizaremos a classificação das estratégias de tutoramento, tendo como base as perguntas. É pertinente ressaltar que o termo material didático será entendido, nesta perspectiva de análise, como um material impresso, estruturado, a fim de ser utilizado como instrumento para o processo de ensino-aprendizagem por professor e alunos (Peralta, 2003).

\section{ESTRATÉGIAS DE TUTORAMENTO}

Tutorial/tutoramento, neste estudo, segue o Modelo Holístico de Richter, onde assume um conceito de inspiração vygotskiana, Neste modelo, o tutoramento é entendido como:

\footnotetext{
Um conjunto de instruções explícitas utilizadas para mediar o trabalho do aluno e do professor em sala de aula em Zona de Desenvolvimento Proximal. Ou seja, é um instrumento que o professor utiliza para "pilotar" a cognição do aluno em direção aos resultados das atividades de leitura considerados desejáveis para a construção das microhabilidades (RICHTER et al, 2006. s/n).
}

Tutorando o aprendiz, o professor poderá assistir o seu desenvolvimento cognitivo ao longo do curso (na resolução das tarefas progressivamente mais complexas) e também poderá apoiá-lo em situações conflitantes, sendo que a parte que cabe ao aluno no processo é realizar as atividades em contexto metacognitivo visando à apropriação progressiva - em parte implícita, em parte reflexivamente — dos conhecimentos relevantes 5 .

Então, pautados no estudo das perguntas e no conceito de tutorial, partimos para a classificação dos tipos de estratégias escritas de tutoramento, às quais nos delimitaremos neste estudo. Enfatizamos o termo escritas, a fim de esclarecer que as estra- 
tégias que nos propomos a elaborar aqui deveriam estas presentes no livro didático do aluno e no livro do professor, para que professor e aluno pudessem utilizá-las no trabalho em sala de aula.

Surgem momentos em sala de aula em que muitas vezes, o professor encontra-se despreparado, ou seja, em situações conflitantes sem tempo de parar $\Rightarrow$ pensar $\Rightarrow$ agir. E as estratégias de tutoramento estão presentes para apoiar o trabalho do professor. Por exemplo, o professor pode pensar que 0 aluno aprendeu 0 assunto $X$ porque marcou a resposta certa; mas não raro o aluno chutou ou copiou do colega. Outro problema que surge com freqüência em sala de aula são as "explicações" mal sucedidas do professor. O aluno não entende a "explicação" do professor e, por falta de estratégias de reflexão ou de condução do raciocínio, o professor "joga a toalha" e acaba fornecendo secamente a resposta. Com isso, priva o aluno de sua parte no processo intersubjetivo de construção do conhecimento na ZDP e perpetua o comodismo na sala de aula.

Além desses problemas, existem outros. Os autores de certos materiais didáticos de PLE também deixam de valorizar o conhecimento de mundo do aluno; parecem esquecer que o aprendiz é estrangeiro e não contextualizam o ensino de leitura com a realidade dos alunos. Esses são alguns pontos a que pretendemos dar subsídios para o trabalho do professor e aluno no ensino de PLE.

\section{Quadro 1 - Classificação das estratégias de tutoramento do livro didático do aluno e livro do professor}

\begin{tabular}{|l|c|c|}
\hline Tipos de estratégias & Função & Fundamentação teórica \\
\hline $\begin{array}{c}\text { 1. Estratégia de mo- } \\
\text { nitoramento do } \\
\text { processo }\end{array}$ & $\begin{array}{c}\text { Monitorar o ensino de leitura em relação ao pro- } \\
\text { cesso, "como" se aprende. O professor interage } \\
\text { com o aluno questionando-o: como chegou a } \\
\text { resposta X? Que pistas dadas na atividade fez } \\
\text { com que ele chegasse a resposta X? }\end{array}$ & $\begin{array}{c}\text { Perguntas em direção ao } \\
\text { processo (Gomes, 2002. } \\
\text { p.232) }\end{array}$ \\
\hline $\begin{array}{l}\text { 2. Estratégias de } \\
\text { contextualização }\end{array}$ & $\begin{array}{c}\text { Analisar se existem pistas para relacionar o con- } \\
\text { texto para o foco da atividade, ou se simples- } \\
\text { mente infere uma linha de montagem. }\end{array}$ & $\begin{array}{c}\text { Perguntas que incentivam } \\
\text { os processos de generali- } \\
\text { zação (Gomes, 2002, p. } \\
\text { 234) }\end{array}$ \\
\hline $\begin{array}{c}\text { 3. Estratégias de or- } \\
\text { ganização das ativi- } \\
\text { dades }\end{array}$ & $\begin{array}{c}\text { Verificar em qual tipologia se enquadram as ati- } \\
\text { vidades, se são do tipo integradas ou do tipo } \\
\text { mecanizadas. }\end{array}$ & $\begin{array}{c}\text { Modelo Holístico de Rich- } \\
\text { ter (2006) }\end{array}$ \\
\hline $\begin{array}{c}\text { 4. Estratégias de in- } \\
\text { teração }\end{array}$ & $\begin{array}{c}\text { Investigar se o trabalho realizado pelo professor } \\
\text { e o aluno é interativo }\end{array}$ & $\begin{array}{c}\text { Pergunta de incentivação } \\
\text { (Lucioli, 2002, p. 66) }\end{array}$ \\
\hline $\begin{array}{c}\text { 5. Estratégias de } \\
\text { ampliação de voca- } \\
\text { bulário }\end{array}$ & $\begin{array}{c}\text { Checar como é trabalho o vocabulário no ensino } \\
\text { de leitura. }\end{array}$ & $\begin{array}{c}\text { Pergunta sobre vocabulá- } \\
\text { rio (Lucioli, 2003. p. 66) }\end{array}$ \\
\hline 6. Estratégia de e- & Instigar o aluno a ter diferenciados pontos de & Perguntas que conduzem \\
\hline
\end{tabular}




\begin{tabular}{|c|c|c|}
\hline $\begin{array}{c}\text { mancipação de res- } \\
\text { postas }\end{array}$ & $\begin{array}{c}\text { vistas em relação às respostas das atividades } \\
\text { de leitura. }\end{array}$ & $\begin{array}{c}\text { a mais de uma resposta } \\
\text { (Gomes, 2002. p. 233) }\end{array}$ \\
\hline $\begin{array}{c}\text { 7. Estratégias de re- } \\
\text { versão }\end{array}$ & $\begin{array}{c}\text { Hipotetizar outras estratégias para reverter ex- } \\
\text { plicações más sucedidas }\end{array}$ & $\begin{array}{c}\text { Modelo Holístico de Rich- } \\
\text { ter (2006) }\end{array}$ \\
\hline $\begin{array}{c}\text { 8. Estratégias de co- } \\
\text { nhecimento prévio }\end{array}$ & Explorar o conhecimento prévio do aluno. & $\begin{array}{c}\text { Perguntas que incentivam } \\
\text { os processos de generali- } \\
\text { zação (Gomes, 2002, p. } \\
\text { 234) }\end{array}$ \\
\hline $\begin{array}{c}\text { 9. Estratégias para } \\
\text { pistas e atalhos }\end{array}$ & $\begin{array}{c}\text { Auxiliar o aluno nas atividades, fornecendo pis- } \\
\text { tas e atalhos para a resolução das atividades. }\end{array}$ & $\begin{array}{c}\text { Modelo Holístico de Rich- } \\
\text { ter (2006) }\end{array}$ \\
\hline 10. Estratégias de & $\begin{array}{c}\text { Checar se as atividades de leitura então estrutu- } \\
\text { metacognição }\end{array}$ & $\begin{array}{c}\text { Modelo Holístico de Rich- } \\
\text { ter (2006) }\end{array}$ \\
\hline
\end{tabular}

O quadro acima não tem por objetivo classificar quais estratégias pertencem ao livro didático do aluno e quais são pertencentes ao livro do professor. Essa classificação não foi realizada porque os materiais de análise podem possuir estratégias em comum. Na seção de análise dos dados, essa categorização ficará mais bem esclarecida.

Outro fator que consideramos relevante destacar é a respeito de algumas estratégias que não tiveram fundamentação teórica nas perguntas. O Modelo Holístico converge com a fundamentação teórica dos autores citados nas perguntas e propõe ampliar a classificação: estratégias de organização das atividades, estratégias de reversão, estratégias para pistas e atalhos, estratégias de metacognição (Richter e Cavichioli, 2006). Na perspectiva desse modelo, em um contexto de ensinoaprendizagem de línguas, inferimos que o substrato da atividade é a conduta do aluno orientada para a construção de competências e habilidades e coordenada pelo professor numa perspectiva vygotskiana, tendo como fundo a ZDP com sua inerente elasticidade e sua travessia que pode ser metaforizada como uma espiral de complexidade ${ }^{6}$.

\section{METODOLOGIA}

\section{Corpus}

Selecionamos para o corpus deste artigo um livro didático do aluno (LDA) e um livro didático do professor (LP), elaborados para o ensino de Português para estrangeiros (PLE). O interesse em investigar tais materiais didáticos partiu da experiência adquirida como aluna-docente na prática de ensino de PL2. Apesar da disponibilidade de algumas coleções didáticas para o ensino de PLE, o MD utilizado nas aulas era elaborado por mim e por mais duas colegas (a elaboração era orientada pelo coordenador do projeto). As propostas de atividades dos MD entravam em conflito com nossas expectativas, nossos valores, nossas crenças e também não condiziam 
com nossos conceitos em relação ao que seria para nós, alunas-docentes, um bom

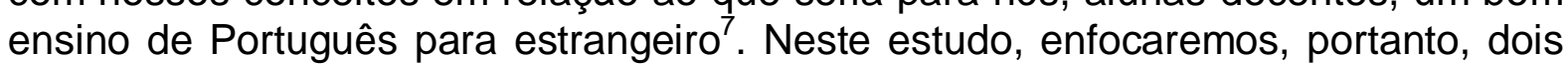
aspectos que causam inquietude nesses materiais: a) Em que medida as estratégias de tutoramento presentes no livro do professor são pertinentes no intuito de ajudar o professor a ampliar o desafio nas atividades de leitura em PLE? b) Que tipo de design tem o tutorial das atividades de leitura do livro didático do aluno, e em que medida esse modelo suscita o desafio das atividades de leitura em PLE?

\section{Procedimentos de análise}

Num primeiro momento, será feito um levantamento das estratégias de tutoramento presentes nos materiais didáticos, corpus de análise deste estudo. Ressaltávamos, aqui, que pode haver a recorrência de outras ET, sendo essas, por sua vez, também acrescentadas na classificação das ET. Na segunda etapa, faremos a análise do corpus, utilizando a Teoria da Atividade de Leontiev, a qual analisa a estrutura da atividade humana, com base em três níveis de funcionamento - a atividade, as ações e as operações. De acordo com Leontiev (1988), a atividade está diretamente associada à motivação, que surge na tentativa de alcançar determinado objetivo ligado a uma necessidade sentida subjetivamente. Movido por esta motivação, o individuo realiza ações que levem a satisfazer seu desejo. A partir da definição dos objetivos conscientes, as condições externas (contexto) vão determinar o conjunto de "passos" que deverão ser realizados no sentido de atingir o que foi proposto. Estes passos, formas tipificadas de conduta, são as operações.

\section{ANÁLISE DOS MATERIAIS DIDÁTICOS}

\section{Análise do Livro Didático do Aluno}

No livro didático do aluno, as seções destinadas ao ensino de leitura vêm denominadas como atividades e leitura suplementar. Conforme informações retiradas da apresentação da estrutura geral do LP, a leitura suplementa aborda assuntos variados da cultura brasileira (música, danças, lendas etc) e informações históricas sobre algumas cidades brasileiras.

Em relação ao vocabulário, que aparece nestas seções, ele apresenta um grau maior de dificuldade. Nas palavras do(a) autor(a), "objetiva que o aluno entre em contato com o vocabulário passivo de cada um desses textos, dando-Ihe, ao mesmo tempo, condições de empregá-lo de acordo com sua necessidade". A seção de atividades tem como propósito trabalhar a produção e compreensão de textos, bem como informações sobre a cultura popular brasileira.

O LDA apresenta treze unidades, estruturadas da seguinte forma: motivação, diálogos, conteúdo gramatical, expansão vocabular, atividades e a leitura suplementar. Passaremos, neste momento, a investigar nas seções de leitura o tipo de design do tutorial das atividades de leitura do livro didático do aluno, ou seja, que ET são disponibilizadas ao aluno. 


\section{Quadro 2 - Apresentação das estratégias de tutoramento do livro didático do aluno}

\begin{tabular}{|c|c|c|}
\hline Unidade & Texto & Estratégias de Tutoramento (ET) \\
\hline 1 & O jangadeiro (leitura suplementar) & -Ausência de ET \\
\hline 2 & Festas religiosas, (leitura suplementar) & -Ausência de ET \\
\hline 3 & $\begin{array}{l}\text { 1) Sinal fechado (samba de Paulinho da Viola) (a- } \\
\text { tividades) } \\
\text { 2) Belo Horizonte, (leitura suplementar) }\end{array}$ & $\begin{array}{l}\text {-Ausência de ET } \\
\text { - Texto } 1 \text { - pretexto gramatical. }\end{array}$ \\
\hline 4 & $\begin{array}{l}\text { 1) Construção (música de Chico Buarque) } \\
\text { 2) O pão de açúcar (leitura suplementar) }\end{array}$ & $\begin{array}{l}\text { - Ausência de ET } \\
\text { - Texto } 1 \text { - pretexto gramatical. }\end{array}$ \\
\hline 5 & $\begin{array}{l}\text { 1) Conversa de botequim (música de Noel Rosa) } \\
\text { (atividades) } \\
\text { 2) A capoeira (leitura suplementar) }\end{array}$ & $\begin{array}{l}\text { - Ausência de ET } \\
\text { - Texto1 - atividades interpretativas. }\end{array}$ \\
\hline 6 & A vitória régua (leitura suplementar) & - Ausência de ET \\
\hline 7 & $\begin{array}{l}\text { 1) Lembrança do mundo antigo (Carlos Drum- } \\
\text { mond de Andrade) (atividades) } \\
\text { 2) Valsa brasileira (Edu Lobo e Chico Buarque) (a- } \\
\text { tividades) } \\
\text { 3) Danças Brasileiras (leitura suplementar) }\end{array}$ & $\begin{array}{l}\text { - Ausência de ET } \\
\text { - Texto } 1 \text { - pretexto gramatical. } \\
\text { - Texto } 2 \text { - pretexto gramatical }\end{array}$ \\
\hline 8 & $\begin{array}{l}\text { 1) Horóscopo (atividades) } \\
\text { 2) Gênero publicidade (atividades) } \\
\text { 3) O padeiro (leitura suplementar) }\end{array}$ & $\begin{array}{l}\text { - Ausência de ET } \\
\text { - Texto } 1 \text { - pretexto gramatical. } \\
\text { Texto } 2 \text { - atividades interpretativas. } \\
\text { Texto } 3 \text { - atividades interpretativas. }\end{array}$ \\
\hline 9 & $\begin{array}{l}\text { 1) Remédios Caseiros (atividades) } \\
\text { 2) O pantanal (leitura suplementar) }\end{array}$ & $\begin{array}{l}\text { - Ausência de ET } \\
\text { Texto } 1 \text { - atividades interpretativas. }\end{array}$ \\
\hline 10 & $\begin{array}{l}\text { Minas gerais: Cidades históricas (leitura suple- } \\
\text { mentar) }\end{array}$ & $\begin{array}{l}\text { - Ausência de ET } \\
\text { - Atividades interpretativas. }\end{array}$ \\
\hline 11 & $\begin{array}{l}\text { 1) Gênero publicidade (atividades) } \\
\text { 2) Casa no campo (Zé Rodrix) }\end{array}$ & $\begin{array}{l}\text { - Ausência de ET } \\
\text { Texto } 1 \text { - pretexto gramatical e ativi- } \\
\text { dades interpretativas } \\
\text { Texto } 2 \text { - atividades interpretativas }\end{array}$ \\
\hline 12 & 1) Gênero carta (atividades) & - Ausência de ET \\
\hline
\end{tabular}




\begin{tabular}{|l|l|l|}
\hline \multirow{2}{*}{} & \multicolumn{1}{|c|}{ Recado ao senhor 903 (leitura suplementar) } & $\begin{array}{l}\text { Texto 1 - pretexto gramatical e ativi- } \\
\text { dades interpretativas } \\
\text { Texto 2 - atividades interpretativas }\end{array}$ \\
\hline 13 & Dar um jeitinho (leitura suplementar) & $\begin{array}{l}\text {-Ausência de ET } \\
\text { Pretexto gramatical e atividades in- } \\
\text { terpretativas }\end{array}$ \\
& & \\
\hline
\end{tabular}

A partir do quadro 2, verificamos a ausência das estratégias de tutoramento. Simplesmente o texto é usado como pretexto, tornando-se, dessa forma, também ausentes as atividades de leitura. Entretanto, ressaltaremos, mesmo assim, algumas $\mathrm{ET}$, as quais consideramos pertinentes para ampliar o desafio no ensino de leitura de PLE.

Tanto no tópico atividades como no tópico leitura suplementar são enfocados assuntos relacionados a cultura brasileira. Mapeando os textos, percebemos que eles são bastante ricos neste aspecto (trabalham com gêneros textuais variados, música, publicidade, carta, por exemplo). Mas mesmo que a proposta do livro não tenha como objetivo principal trabalhar cultura, apenas enfocar o assunto, ou seja, acrescentar informações para o conhecimento do aluno, torna-se difícil para o aprendiz estrangeiro entender o texto e decifrar os significados contidos nele, porque não existe nenhum tipo de estratégias que monitoram o aluno neste trabalho.

Considerando músicas, publicidades, por exemplo: o aluno terá grande dificuldade de entender o conteúdo desses textos, e assim enriquecer seu conhecimento, porque em momento algum os autores do LDA contextualizam estes textos (estratégias de contextualização). Não existem pistas para relacionar o contexto com o foco da atividade. O que temos é uma linha de montagem de atividades com propósitos bem definidos, atividades interpretativas e atividades gramaticais - 1) Sublinhe, no texto da página anterior, todos os verbos que estão no pretérito imperfeito do indicativo; 2) Passe os verbos do exercício 1 para o presente do indicativo; 3) Leia o texto com atenção e faça um resumo (Unidade 7. Texto: Lembrança do mundo antigo).

Outro ponto a ser destacado, no LDA, é o conhecimento prévio do aluno (estratégias de conhecimento prévio), que é totalmente ignorado nas atividades. Ou as atividades e o próprio texto são trabalhados na hipótese de que o aluno já tem conhecimento sobre o assunto, ou, ao contrário, os conteúdos são meramente apresentados sem uma preocupação explícita com o que o aluno possa ou venha a aprender. As atividades são destinadas diretamente para a compreensão do texto: 1) Compreensão do texto: a) Qual o maior centro de música barroca do país?; b) Onde se encontra o maior número de obras de Aleijadinho? C) Quem foi o Mestre Ataíde? etc. (Unidade 10. Texto Minas Gerais, Cidades Históricas)

Van Dijk e Kintsch (1983, apud FARNHAM-DIGGORY, 2000) ressaltam a relevância destas duas estratégias (contextualização e conhecimento de mundo) para a construção das microestruturas. Elas são importantes, porque segundo os autores, se trabalhadas podem seguir em direção ao sinal contextual, fornecendo o tipo de texto que esta sendo lido. E os conhecimentos que o aprendiz já possui, tais como cren- 
ças e experiências culturais podem facilitar a compreensão e a contextualização do texto. Além das estratégias mencionadas, consideramos também pertinente a presença de outras estratégias no LDA, sendo elas as estratégias de organização das atividades, as estratégias de ampliação de vocabulário e as estratégias de metacognição.

As estratégias de organização das atividades têm como propósito verificar o tipo de atividade, estruturalmente falando - se são integradas ou mecanizadas. Consideramos atividades integradas, neste contexto, aquelas que valorizam contexto, texto, vocabulário, aspectos gramaticais (forma), propósito comunicativo (função). Ou seja, atividades que estruturam o ensino como um todo integrado, e não como um saber fragmentado, dividido, em que o vocabulário, formas, atos de fala são separados da leitura como habilidade a construir. No livro didático do aluno aqui analisado, as atividades não são integradas, o livro está estruturado em seções, diálogos, expansão vocabular, conteúdo gramatical, leitura, por exemplo.

O vocabulário também é um aspecto importante que merece destaque. Como ele é trabalhado no ensino de leitura? Quais estratégias são usadas para ampliar o vocabulário? No corpus de análise, são selecionadas algumas palavras que o autor pressupõe que o aluno estrangeiro terá dificuldade, sendo elas destacadas e acompanhadas de seu significado. Assim o aluno entra em contato com o vocabulário passivo do texto, dando-Ihe, ao mesmo tempo, condições de empregá-lo de acordo com sua necessidade (informação retirada do livro) - Vocabulário: 1) fanfarras-uma banda de música formada por instrumentos de sopro; 2) improvisar: falar sem preparação inventar às pressas (Unidade 7. Texto Danças brasileiras).

Será que alguém aprendendo algo de forma passiva terá condições de aplicar tal conhecimento ativamente? Será que listas de vocabulário passivo são importantes para suprir as necessidades dos alunos? Considerando tais questionamentos, Richter, ressalta:

É desabonador para um material didático propiciar meramente listas de palavras ou definições do dicionário de novas palavras. Um agravante disso seria fornecer, em cada texto de uma unidade de leitura, listas de palavras "préprocuradas", que passivizam o aluno ao desestimulá-lo ao uso do dicionário - sem falar nas palavras ensinadas em isolamento ou fora de contexto, que desestimulam o uso de pistas contextuais. (RICHTER, 2005, p.9)

Ao contrário da citação, se as atividades forem bem formuladas, os materiais didáticos podem fornecer aos alunos, segundo Richter (Ibidem, p.9), ferramentaria cognitiva apta para enriquecimento de vocabulário a posteriori - por exemplo, os alunos poderão seguir pistas da relação palavra-contexto e/ou decompor palavras em seus morfemas e testá-los no entorno textual.

Outra estratégia considerada de peso neste estudo é aquela que se preocupa em checar se as atividades de leitura então estruturadas com o intuito de trabalhar a metacognição do aluno. Aqui, as atividades deveriam estar encadeadas, o aluno recebe o input, ou seja, dados que formam o ponto de partida para as tarefas (Nunan, 1989). E o professor tem expectativas didáticas a respeito do output, que é o "retorno" obtido do aluno (material lingüístico produzido) a partir do input, em função da conduta discente ditada pelas tarefas. Se estas estiverem realmente encadeadas, o 
output do aluno servirá de input para a resolução das tarefas seguintes (embora esta diretriz possa ter exceções). Mas, infelizmente, as atividades do livro didático do aluno não estão estruturadas a fim de atender este principio.

Kleiman (2004) destaca que em uma atividade metacognitiva, o aluno reflete sobre o próprio saber, o que pode tornar esse saber mais acessível a mudanças. A autora acrescenta que:

Refletir sobre o conhecimento e controlar os nossos processos cognitivos são passos certos no caminho que leva à formação de um leitor que percebe relações, e que forma relações com um contexto maior, que descobre e infere informações e significados mediante estratégias cada vez mais flexíveis e originais. (Kleiman, 2004, p.9-10)

Torna-se relevante nesta perspectiva diferenciar as atividades cognitivas e as atividades metacognitivas na leitura. Para Leffa (1996, apud JOU e SPERB, 2003, p.18) essas atividades deveriam ser classificadas, não pelo critério de envolvimento de consciência, como faz Brown (1980, apud JOU e SPERB, 2003), mas pelo conhecimento utilizado para executar tal atividade, ou seja, a ativação dos conhecimentos declarativos ou procedurais. Sternberg (2000) define o conhecimento declarativo como um conhecimento consciente e explicito. E conhecimento procedural, como inconsciente, implícito e automático. Retomando Leffa (1996), dizemos, então, que o conhecimento declarativo (saber o quê) envolve a consciência da tarefa a ser executada. Desse modo, esse tipo de conhecimento se identifica com as atividades cognitivas. E o conhecimento procedural (saber como) preocupa-se em saber sobre a execução da tarefa, tendo ciência dos processos conscientes utilizados.

Dessa forma não foi possível delinear que tipo de tutorial têm as atividades de leitura do LDA, porque o tutorial está ausente. Tutorial é entendido, neste estudo, como um conjunto de estratégias que tem como finalidade mediar/tutorar o trabalho do professor e aluno, suscitando o desafio nas atividades de leitura. Desafiar é mediar/tutorar o aprendiz, dando-Ihes condições para que construa seu conhecimento, bem como fazer com ele se envolva no processo de aprender de forma consciente.

Tendo em vista a Teoria da atividade, como metodologia norteadora desta pesquisa, torna-se relevante ressaltar que Leontiev (1988) analisa a estrutura da atividade humana com base em três níveis de funcionamento - a atividade, as ações e as operações.

O nível das atividades corresponde ao material didático como gênero, que é visto neste contexto como um instrumento mediador do processo ensino-aprendizagem de PLE. Tal sistema de atividade é orientado por valores associados às necessidades a serem satisfeitas e, por sua vez, orienta o nível imediatamente inferior, o das ações (elaboração do material didático, design das tarefas etc).

Ao analisarmos as seções de leitura, constatamos que ela está direcionada a atender dois propósitos exclusivos: trabalhar o texto como pretexto para fins gramaticais e interpretativos. Podemos dizer que nesse material o ensino de leitura esvazia seu valor, porque ao mesmo tempo em que não atende às necessidades de se trabalhar leitura, é usado para fins outros. 
Segundo Leontiev (1992, apud, LIBÂNEO, 2006, p12-13), atividade surge de necessidades, que impulsionam motivos orientados para um objeto. A atividade implica um sentido a dar a uma ação ou encadeamento de ações. Leontiev exemplifica utilizando a atividade de ler um livro. Se lermos um livro somente para passar em um exame, não é atividade, é ação, porque a leitura pela leitura não é um objetivo significativo a ponto de estimular (essa) ação. A atividade é a leitura do livro motivada pelo que este significa (motivo) para o possível leitor. Vale dizer, quando o motivo da atividade passa para o objeto da ação, a ação transforma-se numa atividade.

Esse mesmo exemplo reflete-se em nossa análise, em que a atividade consiste em ensinar-aprender leitura. Mas, ao contrário disso, as atividades de leitura servem de pretexto para trabalharmos tudo, menos leitura. Sendo assim, da mesma forma que o exemplo acima, leitura como pretexto também não é atividade, e sim uma ação, porque o motivo da atividade não é considerado como objeto da ação. Perdendo seu motivo originário, automaticamente anulam-se o nível das ações e das operações, porque os objetivos propostos, ou seja, as ações que podem ser efetuadas para satisfazer a necessidade, não condizem com a necessidade associada à atividade - construir uma competência de leitura. E como as operações dependem das condições de execução da ação, elas também se anulam (ou seja, ninguém adquire competência como leitor fazendo de textos meros pretextos). Como as ações gerenciam o nível imediatamente inferior - o das operações - neste último estão inclusas, no espaço da intersubjetividade pedagógica, as estratégias de tutoramento, que se referem (na forma de microhabilidades) aos inúmeros procedimentos orientados que o aluno realizará para alcançar seu objetivo, internalizando-os progressivamente. A operação é a tecnificação da ação e, em geral, realiza-se automaticamente (Asbahr, 2005, p.110).

\section{Análise do Livro do professor}

O guia pedagógico do professor tem como objetivo fornecer diretrizes necessárias a uma boa utilização de todo o material na sala de aula. Fornece também sugestões de exploração parcial dos segmentos explicados, seguidas de uma orientação detaIhada das Unidades 1 a 4 . Nas demais, são destacadas apenas as questões que possam apresentar uma certa dificuldade ${ }^{8}$. A partir, daí, passaremos à análise de que tipo de estratégias de tutoramento este material didático oferece ao professor com o intuito de ajudar a ampliar o desafio discente nas atividades de leitura. Percorrendo as unidades do LP, constatamos um fato repetido na análise do LDA, a acentuada rarefação das estratégias de tutoramento. Estas, a rigor, não estavam totalmente ausentes, visto que nas unidades 1 e 2 encontramos proposto o uso da estratégia de conhecimento prévio, tendo esta como propósito trabalhar as ilustrações da leitura - o que é isso?; A Festa do Divino está representada por qual figura?.Nas demais unidades, entretanto, as estratégias de tutoramento seguem virtualmente ausentes. Apenas sugestões de atividades aparecem propostas ao professor - $\mathrm{co}$ mo sugestão, pode-se utilizar o assunto do texto para uma conversação dinâmica na sala de aula sobre a vida moderna, o transito, a correria, etc.

Outro aspecto que enfocamos, novamente, é a questão de os materiais didáticos proporem o trabalho (inter)cultural, sem trabalhar o contexto dos itens culturais apre- 
sentados. Podemos aqui nos questionar: até que ponto este trabalho (inter)cultural faz sentido para o aluno?

Além das estratégias já mencionadas, consideramos indispensáveis a presença de três outras no LP, a saber: a) estratégia de monitoramento do processo, que tem como função monitorar o ensino de leitura em relação ao processo, o "como" se aprende. O professor interage com o aluno questionando-o: como chegou à resposta $X$ ? Que pistas dadas na atividade fez com que ele chegasse à resposta X?; b) estratégias de reversão, que objetivam hipotetizar outras estratégias para reverter explicações mal sucedidas; c) estratégias para pistas e atalhos, que se destinam a auxiliar o aluno nas atividades, apontando possíveis caminhos para a resolução das atividades.

O livro/guia do professor, segundo Richter e Cavichioli (2006), precisa deixar de desempenhar um papel apenas prescritivo, transformando o professor em um mero aplicador ou portador da proposta do autor. Precisa, isto sim, dar suporte para que o professor possa avançar e desafiar o aluno nas atividades, bem como acompanhar/tutorar o processo cognitivo dos aprendizes. O professor, desta maneira, passaria de instrutor a formador.

O nível da atividade do livro/guia do professor corresponde também ao material didático como gênero, igualmente, como é visto o livro didático do aluno, um instrumento que medeia o processo de ensino-aprendizagem de Português Língua Estrangeira. Neste nível, o motivo principal do LP é fornecer orientações, ou seja, dirigir o professor a fim de que ele possa fazer uma boa utilização de todo o material na sala de aula (proposta do LP). Com o motivo claramente definido, é preciso verificar se ele se encontra de acordo com o objetivo das ações. Para tanto, o que observamos é a incompatibilidade entre motivo e objetivo. Na verdade, o LP preocupa-se, quase que exclusivamente, em dar sugestões de trabalho que não auxiliam, cognitivamente, no desempenho do aluno.

Numa perspectiva vygotskiana de ensino-aprendizagem, ausentes as ações, obviamente estarão também ausentes as operações e, com isso, no presente caso, a construção das competências. Segundo Leontiev (1988), as ações apresentam dois aspectos: o intencional e o operacional, sendo este último a forma como se realizam as operações. Cada ação inclui diferentes operações que dependem das condições de execução da ação (Asbahr, 2005, p.110). As operações seriam o meio que o professor utilizaria para controlar o processo cognitivo do aluno. Em outras palavras, é por intermédio das operações que o professor acompanharia os processos remotos, que vão passando gradativamente do controle do professor para o aluno. Na medida em que o professor passa apenas a monitorar o aprendiz, isso significa que houve a internalização ${ }^{9}$ do conhecimento (meta consagrada da ZDP) ${ }^{10}$.

\section{CONSIDERAÇÕES FINAIS}

Concluindo parcialmente este estudo, verificamos que os autores dos materiais didáticos analisados em momento algum mostram preocupação em dar assistência ao desempenho do professor e do aluno. O livro do professor (LP), que deveria ajudar o 
professor no gerenciamento das ações, desempenha um papel apenas sugestivo, transformando o professor em um mero aplicador ou portador da proposta do autor. O livro didático do aluno (LDA), além de não apresentar nenhum tipo de estratégia de tutoramento, usa as seções de leitura para trabalhar o texto como pretexto e para fins interpretativos. Podemos dizem que as tarefas em geral assumem certo ar behaviorista, mera conduta automatizada de repetir conteúdos e reproduzir de forma mecânica o que está no livro didático.

A Teoria da Atividade, metodologia norteadora desta análise, estipula que pesquisar a atividade requer a análise de sua estrutura (necessidade, objeto e motivo) e das relações entre seus componentes. Requer, pois, descobrir qual é o motivo da atividade, discriminar quais são as unidades constitutivas da atividade e que função estão desempenhando na prática social focalizada.

\section{BIBLIOGRAFIA}

ASBAHR, ASBAHR, F. S.F. A pesquisa sobre a atividade pedagógica: contribuições da teoria da atividade. Disponível em: www.scielo.br/pdf/rbedu/n29/n29a09.pdf. Acesso em 10 de ago de 2006.

BAZERMAN, C. Gêneros textuais, tipificação e interação. Tradução e adaptação de J. C. Hoffnagel. São Paulo: Cortez, 2005.

BRONCKART, J. P. Atividade de linguagem, textos e discurso: por um interacionismo sócio-discursivo. Tradução de A. R. Machado, P. Cunha. São Paulo: EDUC, 1999.

CORACINI, M.J.R.F. Pergunta-resposta na aula de leitura: um jogo de imagens. In: CORACINI, M.J.R.F. (Org) O jogo discursivo na aula de leitura: língua materna e língua estrangeira. Campinas. S P: Pontes, 1995, p. 75-84.

DOFF, A. Teach English - a training course for teachers. Cambridge: CUP, 1988.

FARNHAM-DIGGORY, S. Advanced Reading and writing. In: FARNHAMDIGGORY, S. Cognitive process in education. Nova York: Harper Collins, 1992, p. 343-367.

GALLIMORE, R; THARP, R. O pensamento educativo na sociedade: ensino, escolarização e discurso escrito. In: MOLL, L.C. Vygotsky e a educação: implicações pedagógicas da psicologia sócio-histórica. Porto Alegre: Artes Médicas, 1996, p. 171-199.

GOMES, C,M.A. Feuerstein e a construção mediada do conhecimento. Porto Alegre: Artes Médicas, 2002.

FRAWLEY, W. Vygotsky e a ciência cognitiva: linguagem e integração das mentes social e computacional. Tradução M.A.G. Domingues. Porto Alegre: Artes Médicas Sul, 2000. 
JOU, G, de; SPERB, T. Leitura compreensiva: um estudo de caso. Linguagem \& ensino, Pelotas, v 6, n 2, p. 13-54, jul/dez. 2003.

KLEIMAN, A. Texto e leitor: aspectos cognitivos da leitura. Campinas, SP: Pontes, 9o ed, 2004.

LEONTIEV, A.N. Uma contribuição à teoria do desenvolvimento da psique infantil. In:_ VYGOTSKY, L.S; LURIA, A.R; LEONTIEV, A N. Linguagem, desenvolvimento e aprendizagem. São Paulo: Ícone: Editora da Universidade de São Paulo, 1988 , p. 59-83.

LIBÂNEO, J.C. A didática e a aprendizagem do pensar e do aprender: a Teoria Histórico-Cultural da Atividade e a contribuição de Vasili Davydov. Disponível em: www.anped.org.br/rbe27/anped-n27-art01.pdf . Acesso em 01 de set de 2006.

LUCIOLI, R.M. As perguntas como mediadoras na construção de conhecimentos. 2003.184p. Dissertação (Mestrado em Lingüística Aplicada) - Pontifica Universidade Católica, São Paulo, 2003.

MAGALHÃES, M.C.C. Contribuições da pesquisa sócio-histórica para a compreensão dos contextos interacionais da sala de aula de línguas: foca na formação de professores. The Especialist, São Paulo, v 17, n 1, p. 01-18, 1994.

MARTINS, V. A arte de perguntar. Disponível em: $<$ http: /www.malhatlantica.pt/ecae-

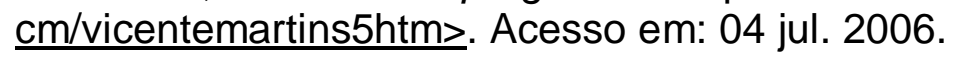

NUNAN, D. Designing tasks for the communicative classroom. Cambridge: University Press, 1989.

OLIVEIRA e PAIVA, V.L.M. de. Estratégias Individuais de aprendizagem de língua inglesa. Letras \& Letras, Uberlândia, v 14, n 1, p.73-88, jul/dez. 1997.

PARÂMETROS CURRICULARES NACIONAIS LÍNGUA PORTUGUESA (Brasil). Ministério da Educação e do Desporto (MEC) versão agosto/1996. Disponível em:<wwww.bibvirt.futuro.usp.br/textos/humanas/educacao/pcns/fundamental >. Acesso em: 20 ago. 2006.

PERALTA, T.M. A atividade docente mediada pelo uso do livro didático. 2003. 147p. Dissertação (Mestrado em Lingüística Aplicada) - Pontifica Universidade Católica, São Paulo, 2003.

RICHTER, M.G. O material didático no ensino de línguas. Linguagens e Cidadania. Santa Maria: UFSM, 2005. Disponível em: $<$ http://www.ufsm.br/linguagens e cidadania >. Acesso em: 21 de nov de 2006.

RICHTER, M.G; CAVICHIOLI, F. O tutorial em livros didáticos de português para estrangeiros. Santa Maria-RS. VI Seminário Internacional em Letras: Margens e Imagens/ /UNIFRA, 2006. CD-ROM. 
RICHTER, M.G; CAVICHIOLI. F; PINTO, C.M. Processos e Fatores Envolvidos na Aquisição de L2 e a Natureza do Conhecimento Lingüístico Adquirido. Porto Alegre RS: $7^{\circ}$ Encontro nacional sobre aquisição da linguagem - ceaal/ PUCRS, 2006. CDOM. (no prelo)

RICHTER, M.G. et al. O modelo holístico como alternativa à formação docente. Florianópolis-SC: I Congresso Latino-americano sobre formação de professores de línguas, 2006. 1 CD-ROM. (no prelo).

SHNEUWLY, B; DOLZ, J. Gêneros textuais e escritos na escola. Tradução e organização de R. Rojo; G.S. Cordeiro.São Paulo: Mercado das Letras, 2004.

STERNBERG, R. Psicologia cognitiva. Porto Alegre: ARTMED, 2000.

\footnotetext{
${ }^{1}$ Talvez o que é considerado por mim como falhas, não é considerada falhas para outros professores. Os textos descontextualizados, as atividades estruturais, o texto como pretexto para trabalhar gramática, por exemplo.

${ }^{2}$ As pesquisas que me refiro, aqui, são realizadas por um grupo de pesquisadores da UFMG desde 1992. Paiva, a autora que cito, é atuante no grupo de pesquisa já referido.

${ }^{3}$ Tutorial, segundo o Modelo Holístico, conceito de inspiração vygotskiana, é um conjunto de instruções explícitas utilizadas para mediar o trabalho do aluno e do professor em sala de aula em Zona de Desenvolvimento Proximal. Ou seja, é um instrumento que o professor utiliza para "pilotar" a cognição do aluno em direção aos resultados das atividades de leitura considerados desejáveis para a construção das microhabilidades.

${ }^{4}$ Richter - comunicação pessoal em 10 de outubro de 2006.

${ }^{5}$ Richter - comunicação pessoal em 05 de setembro de 2006.

${ }^{6}$ Richter - comunicação pessoal em 25 de outubro de 2006

${ }^{7}$ Um bom ensino de Português para estrangeiros, segundo nossa concepção (na época alunas-docentes), deveria valorizar: proposta de um ensino comunicativo (forma - função), atendimento das necessidades do aluno, inserção do aluno estrangeiro no contexto social brasileiro, trabalho com gêneros textuais, abordagem de pontos interculturais, etc.

${ }^{8}$ Informações retiradas da parte introdutória do livro do professor, intitulada Estrutura Geral.

${ }^{9} \mathrm{O}$ conceito de internalização trabalhado na TA quer dizer que o aluno não é apenas passivo, regulado por forças externas que vão moldando, nem somente ativo, regulado por forças internas, mas sim interativo. Isso significa que é na troca com outros sujeitos e consigo próprio que vão se internalizando conhecimentos, papéis e funções sociais, o que permite a construção do conhecimento e da própria consciência.
}

${ }^{10}$ Richter - comunicação pessoal em 05 de setembro de 2006. 